\title{
Clawed toes in the diabetic foot: neuropathy, intrinsic muscle volume, and plantar aponeurosis thickness William R Ledoux ${ }^{* 1,2,3}$, Jason Schoen ${ }^{1}$, Matthew Lovell ${ }^{1}$ and Elizabeth Huff ${ }^{1}$
}

\author{
Address: ${ }^{1}$ RR\&D Center of Excellence, Department of Veterans Affairs, Seattle, WA, USA, ${ }^{2}$ Departments of Mechanical Engineering, University of \\ Washington, Seattle, WA, USA and ${ }^{3}$ Orthopaedic \& Sports Medicine, University of Washington, Seattle, WA, USA \\ Email: William R Ledoux* - wrledoux@u.washington.edu \\ * Corresponding author
}

from Ist Congress of the International Foot \& Ankle Biomechanics (i-FAB) community

Bologna, Italy. 4-6 September 2008

Published: 26 September 2008

Journal of Foot and Ankle Research 2008, I (Suppl I):O2 doi:I0.I I86/I757-I I46-I-SI-O2

This abstract is available from: http://www.jfootankleres.com/content/I/SI/O2

(c) 2008 Ledoux et al; licensee BioMed Central Ltd.

\section{Introduction}

Clawed toes, defined as extension of the metatarsophalangeal joint (MTPJ) and flexion of the proximal and distal interphalangeal joints (IPJ), have been associated with the diabetic foot. One theory states that this deformity is caused by an imbalance between the extrinsic and intrinsic foot muscles $[1,2]$. However, Bus et al. found a $73 \%$ decrease in intrinsic muscle cross sectional area between diabetic neuropathic patients and controls, but only 2 of 8 neuropathic patients had toe deformities [3]. Anderson et al. found that diabetic neuropathic patients had a little more than $50 \%$ of the intrinsic muscle volume of either controls or non-neuropathic diabetic patients, but none of the diabetic neuropathic patients had toe deformities [4]. Others have found a link between plantar apo-neurosis (PA) dysfunction and clawed toes $[5,6]$ and between diabetes and a thicker PA [7-9]. The purpose of this study was to explore the relationship between claw toes, neuropathy, intrinsic muscle volume and PA thickness.

\section{Methods}

We enrolled 40 diabetic subjects in 4 groups: G1) neuropathic, claw toes, G2) neuropathic, no claw toes, G3) nonneuropathic, claw toes, and G4) non-neuropathic, no claw toes. We have analyzed a subset for this abstract (G1: $\mathrm{n}=6, \mathrm{G} 2: \mathrm{n}=4, \mathrm{G} 3: \mathrm{n}=6, \mathrm{G} 4: \mathrm{n}=4)$. The presence of claw toes was determined via clinical exam and neuropathy was defined as insensitivity to a $10 \mathrm{~g}$ monofilament. Partial weight-bearing CT scans were taken for each foot. Intrinsic muscle volume was determined by segmenting each foot using MultiRigid; data were normalized to total foot volume. PA thickness was measured at $1 / 5$ the distance from the heel to the base of the first metatarsal using ImageJ. A two-way analysis of variance was used to test for interaction and significance $(\mathrm{p}<0.05)$.

\section{Results}

There was significant interaction between foot deformity and neuropathy $(\mathrm{p}=0.02)$. Feet with both neuropathy and foot deformity had lower mean volume than all the other groups, i.e., volume was reduced only when feet were both neuropathic and had deformity (Table 1).

Mean PA thickness was significantly higher for feet with foot deformities than those without $(\mathrm{p}=0.019)$ (Table 2$)$. Thickness was also higher in neuropathic feet than in nonneuropathic feet, but this difference was not significant ( $p$ $=0.14)$. While the data suggests that thickness was highest in feet that had both neuropathy and deformity beyond the additive effects of each factor separately, the interaction between deformity and neuropathy was not significant $(\mathrm{p}=0.2)$.

Table I: Intrinsic muscle volume (mean \pm SD)

\begin{tabular}{lll}
\hline & claw toes yes & claw toes no \\
\hline neuropathy yes & $0.130 \pm 0.037$ & $0.191 \pm 0.008$ \\
neuropathy no & $0.198 \pm 0.018$ & $0.192 \pm 0.034$
\end{tabular}


Table 2: PA thickness (mean \pm SD)

\begin{tabular}{lll}
\hline & claw toes yes & claw toes no \\
\hline neuropathy yes & $4.57 \pm 1.19$ & $2.96 \pm 0.22$ \\
neuropathy no & $3.51 \pm 0.99$ & $3.00 \pm 0.20$ \\
\hline
\end{tabular}

\section{Conclusion}

Our pilot study demonstrates that neuropathic feet with claw toes have less intrinsic muscle volume than the other groups. The same feet also had thicker PA, suggesting that both intrinsic muscle atrophy and PA dysfunction are required for the development of claw toes. The specific mechanism of clawing with a thicker PA (as opposed to a ruptured PA, as seen previously $[5,6]$ ) is not yet understood.

\section{Acknowledgements}

The Department of Veterans Affairs

\section{References}

I. Boulton: M Clin NA 1988, 72:1513-30.

2. Myerson, Shereff : JBJS-Am 1989, 71:45-9.

3. Bus, et al.: Dia Care 2002, 25: $1444-50$.

4. Andersen, et al.: Dia Care 2004, 27:2382-5.

5. Pardiwala, Henry: Ft \& Ank Sur 200I, 7:197-200.

6. Taylor : JB/S-Br I95I, 33-B:539-542.

7. Bolton, et al.: Cl Biom 2005, 20:540-6.

8. D'Ambrogi, et al.: Dia Med 2005, 22: I7I3-9.

9. Giacomozzi, et al.: Cl Biom 2005, 20:532-9.

Publish with Bio Med Central and every scientist can read your work free of charge

"BioMed Central will be the most significant development for disseminating the results of biomedical research in our lifetime. "

Sir Paul Nurse, Cancer Research UK

Your research papers will be:

- available free of charge to the entire biomedical community

- peer reviewed and published immediately upon acceptance

- cited in PubMed and archived on PubMed Central

- yours - you keep the copyright

Submit your manuscript here:

http://www.biomedcentral.com/info/publishing_adv.asp 